\title{
Vulnerable Populations
}

\author{
Ankit Jaiswal, MA (Disaster Management)
}

Jamsetji Tata Center for Disaster

Management, TISS, Mumbai, India

Prehosp Disaster Med 2011;26(2):138

Correspondence:

E-mail: jaiswal.ankit.20@gmail.com

Online publication: 3 May 2011

doi: 10.1017/S1049023X1100015X
This letter is in response to the review by Richard Zoraster titled "Vulnerable Populations: Hurricane Katrina as a Case Study" published in Volume 25, Number 1 of Prehospital and Disaster Medicine. ${ }^{1}$ The identification and analysis of the "gap" in disaster planning was brought to light. I agree with the author that ecological disasters are not egalitarian, which calls for emphasis on "socio-economic" disparities for an inclusive disaster management.

Natural hazards have occurred since time immemorial, and so has their impact on human civilization. Zoraster's focal point is that irrespective of the type of country, those worst hit are those who are vulnerable, which include the poor, senior citizens, ethnic minorities, people who are geographically isolated, people who are homeless or sheltered, and those who reside in high-risk areas. The point he has made about the socio-economic disparities not being acknowledged or considered during the process of disaster mitigation, disaster preparedness, disaster response, and rehabilitation and recovery is very much acceptable. Asia is considered to be the most vulnerable of all the continents. Within Asia, 24\% of deaths due to disasters occur in India on account of its size, population, and vulnerability. ${ }^{2}$ According to the $10^{\text {th }}$ Five Year Plan document about $55 \%$ of the total area in India is in Seismic Zones III-V and vulnerable to earthquakes. Areas on the east coast and in Gujarat are vulnerable to cyclones. Between 1988 and 1997, disasters killed on an average 5,116 people and affected 24.79 million people in India each year. The acute disparity in the socio-economic situation in India based on caste, creed, religion, language, status, and geographical location (rural and urban) is a concern because disasters due to natural hazards will be more damaging to the vulnerable than the rest of the population. For example, in the first week of the Gujarat earthquake in 2001, there was a high number of surgeons in the earth quake-hit region, but they could not conduct surgery because of lack of equipments and electricity. ${ }^{2}$ When a Super Cyclone hit Orissa in 1999, the district of Jagatsinghpur had only three cyclone shelters. The wireless system of the police failed because there were no radio towers that withstood the wind. These infrastructure problems coupled with the lack of awareness cost about 10,000 lives. ${ }^{2}$

I am not against the system currently in place, but it is important to understand whether or not the "inequalities" or "diversities" are kept in mind while developing plans. Governmental measures always should be more people-centric and incorporated with indigenous knowledge of local communities, while also considering social "inequalities" and "diversities". Special consideration should always be taken for vulnerable section of society, so that they can be more resilient. Zoraster's conclusion that many risks are "societal", not physiological, is indeed a stepping stone to bring about a transformation to a more inclusive approach to disaster management.

\section{References}

1. Zoraster R: Vulnerable populations: Hurricane Katrina as a case study. Prehosp Disaster Med 2010;25(1):74-78.

2. Centre for Budget and Governance Accountability: Public policy towards natural disasters in India: Disconnect between reality and situations. Available at http://www.cbgaindia.org/publications/working_papers/Public\%20 Policy\%20towards\%20Natura1\%20Disasters\%20in\%20India.pdf. Accessed 27 June 2010. 